\title{
Efficacy and safety of reducing post-traumatic hidden blood loss with early tranexamic acid intervention in elderly patients with intertrochanteric fracture: $A$ retrospective analysis
}

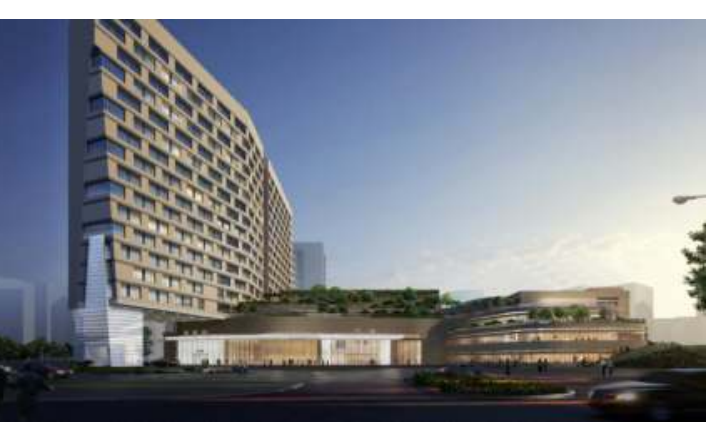

Huixu Ma ${ }^{1}$, Hairuo Wang1, Xiaohua Chen ${ }^{1}$, Zexiang Xu1 ${ }^{1}$, Fuming, Wang1, Tao He ${ }^{1}$, Ji Wang1, Xiaotao Long1, Xi Liu ${ }^{2}$

'Department of Orthopaedics, Chongqing General Hospital, Chongqing 400021, China;

${ }^{2}$ Department of Radiology, Chongqing City Hospital of Traditional Chinese Medicine, Chongqing 400022, China

\section{Introduction}

Globally, hip fracture is a frequent cause of morbidity and mortality, particularly among elderly people[1]. Recent studies have confirmed that elderly patients with intertrochanteric fractures exhibit preoperative nonnegligible hidden blood loss (HBL), which can impact functional outcomes and increase mortality by lowering hemoglobin ( $\mathrm{Hgb})$ levels. TXA is a synthetic analogue of an amino acid with biological activity that inhibits plasminogen from dissolving clots; such activity can reduce blood loss and transfusion requirements[2]. Previous studies have shown that TXA reduces total blood loss and the requirement for transfusion in hip arthroplasty and hip fracture surgery[3,4]. Recently, studies describing HBL during the perioperative period following intertrochanteric fractures have been increasing in number $[5,6]$.

\section{Methods}

A retrospective study was conducted with 77 patients (age $\geq 65$ years, injury time $\leq 6 \mathrm{~h}$ ) who presented with intertrochanteric fracture from November 2016 to April 2018. Patients in the TXA group $(\mathrm{n}=39)$ received $1 \mathrm{~g}$ of IV TXA at admission, whereas those in the normal saline (NS) group $(\mathrm{n}=38)$ received an equal volume of saline. Hemoglobin (Hgb) and hematocrit (Hct) were recorded at post-traumatic admission (PTA) and on post-traumatic day (PTD) 1-3. HBL was calculated using the Gross formula. The criterion of blood preoperative transfusion (POT) was as an $\mathrm{Hgb}$ level of $<80 \mathrm{~g} / \mathrm{L}$ or symptomatic anemia (lightheadedness, palpitation, or shortness of breath not associated with other etiologies) in a patient with an $\mathrm{Hgb}$ level of 80-100 g/L[7]. Lower extremity venous ultrasound was performed to detect venous thrombosis.

\section{Data analysis}

Continuous data were analyzed using independentsample t-tests, and the nonparametric alternative (MannWhitney $U$ tests) was used where data were not normally distributed. A chi-square test or Fisher's exact test for difference in proportions was used to estimate differences between groups in categorical variables. The difference was considered statistically significant if $P<$ 0.05

\section{Conflicts of Interest and Sources of Funding:}

This study was supported by Chongqing General Hospital Medical Science and Technology Innovation Fund Project (Y2017MSXM08), and Chongqing Yuzhong district Science and Technology Project (20150131). There are no conflicts of interests.
Table 2. Comparison of post-traumatic outcomes between the TXA

77 patients ( 23 males and 54 females) were finally and NS groups

included. The supplemental TXA group included 39 patients (male:female $=11: 28$ ), and the NS group included 38 patients (male:female $=12: 26$ ). No differences were found between the two groups with respect to age, sex, or body mass index $(\mathrm{P}>0.05$, Table

1). Hgb and Hct on PTD 2 and 3 were statistically highe in the TXA group than in the NS group $(\mathrm{P}<0.05$, Table 2). HBL on PTDs 1-3 were significantly less in the TXA group than in the NS group $(\mathrm{P}<0.05$, Table 2$)$. The preoperative transfusion (POT) rate was significantly lower in the TXA group than in the NS group [TXA, $10.26 \%$ (2.0 U packed RBC in two patients on PTD 4 and $4.0 \mathrm{U}$ packed RBC in two patients on PTD 5) vs. NS, 28.95\% (2.0 U packed RBC in seven patients on PTD and $4.0 \mathrm{U}$ packed RBC in four patients on PTD 4); P $=036$, Table 2]. In the TXA group, 4 patients developed venous thrombosis in the lower limbs, and 3 patients developed lower extremity venous thrombosis in the NS group $(\mathrm{P}=.515$, Table 3$)$.

Table 1: Comparison of general characteristics of patients in the study

\begin{tabular}{llll}
\hline Items & $\begin{array}{l}\text { TXA group } \\
(\mathrm{n}=39)\end{array}$ & $\begin{array}{l}\text { NS group }(\mathrm{n} \\
=38)\end{array}$ & $\mathrm{P}$ \\
\hline Female (\%) & $28(71.79)$ & $26(68.42)$ & $.807 \S$ \\
Age (year) & $78.6 \pm 8.0$ & $78.9 \pm 7.0$ & $.883^{*}$ \\
BMI (kg/m²) & $22.7 \pm 3.1$ & $23.3 \pm 2.6$ & $.476^{\wedge}$ \\
$\begin{array}{l}\text { Length of } \\
\text { trauma to } \\
\text { admission (h) }\end{array}$ & $2.7 \pm 1.2$ & $2.6 \pm 1.2$ & $.831^{\wedge}$ \\
$\begin{array}{l}\text { Receiving } \\
\text { PFNA (\%) }\end{array}$ & $36(92.3)$ & $35(92.1)$ & $.650 \S$ \\
\hline
\end{tabular}

${ }^{*}$ Independent-sample t-tests; ${ }^{\S}$ chi-squared and Fisher's exact test; ${ }^{\wedge}$ Mann-Whitney U test; TXA, Fin mex index; PFNA, proxinal fenot nil antirotation

\begin{tabular}{llll}
\hline Items & $\begin{array}{l}\text { TXA group } \\
(\mathrm{n}=39)\end{array}$ & $\begin{array}{c}\text { NS group }(\mathrm{n}= \\
38)\end{array}$ \\
\hline Hgb (g/L) & & & \\
Hgb PTA & $116.1 \pm 4.6$ & $114.8 \pm 6.7$ & $.288^{*}$ \\
Hgb PTD 1 & $111.2 \pm 5.3$ & $108.6 \pm 7.3$ & $.068^{*}$ \\
Hgb PTD 2 & $105.4 \pm 6.6$ & $100.3 \pm 7.7$ & $.003^{\wedge}$ \\
Hgb PTD 3 & $98.7 \pm 9.4$ & $88.6 \pm 8.2$ & $<.001^{\wedge}$ \\
Hct (\%) & & & \\
Hct PTA & $43.3 \pm 2.4$ & $42.4 \pm 2.2$ & $.128^{\wedge}$ \\
Hct PTD 1 & $39.2 \pm 2.5$ & $38.6 \pm 1.7$ & $.058^{\wedge}$ \\
Hct PTD 2 & $35.8 \pm 3.0$ & $34.3 \pm 2.6$ & $.005^{\wedge}$ \\
Hct PTD 3 & $32.6 \pm 3.8$ & $27.0 \pm 3.0$ & $<.001^{\wedge}$ \\
HBL (mL) & & & \\
HBL PTD 1 & $173.9 \pm 16.0$ & $182.3 \pm 21.0$ & $.021^{*}$ \\
HBL PTD 2 & $238.5 \pm 25.6$ & $254.7 \pm 29.2$ & $.005^{\wedge}$ \\
HBL PTD 3 & $281.2 \pm 23.2$ & $360.1 \pm 40.5$ & $<.001^{\wedge}$ \\
POT rate (\%) & $4(10.26)$ & $11(28.95)$ & $.036 \S$ \\
POT units (U) & 12 & 30 & - \\
\hline
\end{tabular}

Independent-sample t-tests; § chi-squared and Fisher's exact test; 'Mann-Whitney U test; Hct, hematocrit; Hgb, hemoglobin; HBL, hidden blood loss; TXA, tranexamic acid; NS, normal saline; PTA, post-traumatic admission; PTD, post-traumatic day; POT, preoperative transfusion
Table 3: Complications in the TXA and NS groups

\begin{tabular}{|c|c|c|c|}
\hline Items & $\begin{array}{l}\text { TXA group }(\mathrm{n}= \\
39)\end{array}$ & $\begin{array}{l}\text { NS group }(n= \\
38)\end{array}$ & $\mathrm{P} \S$ \\
\hline Vein thrombosis & 4 & 3 & .515 \\
\hline $\begin{array}{l}\text { Pulmonary } \\
\text { embolism }\end{array}$ & 0 & 0 & \\
\hline $\begin{array}{l}\text { Respiratory } \\
\text { infection }\end{array}$ & 4 & 5 & .517 \\
\hline
\end{tabular}

${ }^{\S}$ Chi-squared and Fisher's exact test; TXA, tranexamic acid; NS, normal saline

Conclusions

The most important finding of this study was that the early application of intravenous TXA supplements can reduce the posttraumatic HBL, preoperative transfusion rate, and without increasing the incidence of venous thrombosis, or mortality in elderly patients with intertrochanteric fractures.

References

1.Peeters CM, Visser E, Van de Ree CL, Gosens T, Den Oudsten BL, De Vries J. Quality of life after hip fracture in the elderly: a systematic literature review. Injury 2016; 47:13691382

Poeran J, Rasul R, Suzuki S, Danninger T, Mazumdar M, Opperer M, et al. Tranexamic acid use and postoperative outcomes in patients undergoing total hip or knee arthroplasty in the United States: retrospective analysis of effectiveness and safety. BMJ 2014; 349:g4829.

3. Oremus K, Sostaric S, Trkulja V, Haspl M. Influence of tranexamic acid on post-operative autologous blood retransfusion in primary total hip and knee arthroplasty: a randomized controlled trial. Transfusion 2014; 54:31-41. 4.Tian SW, Shen ZY, Liu Y, Zhang Y, Peng A, et al. The effect of tranexamic acid on hidden bleeding in older intertrochanteric fracture patients treated with PFNA. Injury 2018; 49:1-5.

5.Lei JL, Zhang BF, Cong YX, Zhuang Y, Wei X, Fu Y, et al. Tranexamic acid reduces hidden blood loss in the treatment of intertrochanteric fractures with PFNA: a single-center randomized controlled trial. J Orthop Surg Res 2017; 12:1-6. 6.FOSS NB, Kristensen MT, Kehlet H. Anaemia impedes functional mobility after hip fracture surgery. Age and Ageing 2008; 37: 173-178

7.Huang Z, Xie X, Li L, Huang Q, Ma J, Shen B, Kraus VB, Pei F. Intravenous and topical tranexamic acid alone are superior to tourniquet use for primary Total knee arthroplasty: a 列 2017; 99:2053-2061. 